\title{
Erratum to: Effect of Broodlac Treatment with Insecticides on Population Reduction of Predators and Parasitoids of Lac Insect, Kerria lacca (Kerr)
}

Jai Prakash Singh • Anil Kumar Jaiswal •

Mohammad Monobrullah $\cdot$ P. Patamajhi

Published online: 8 October 2013

(C) The National Academy of Sciences, India 2013

Erratum to: Natl. Acad. Sci. Lett. (2013) 36(4):379-383

DOI 10.1007/s40009-013-0147-x

Unfortunately, in the original article published in Volume 36, Issue 4, the co-author names "A. K. Jaiswal, Mohammad Monobrullah and P. Patamajhi" have been inadvertently missed during the publication process.

The complete author group is given in this erratum.

The online version of the original article can be found under doi:10.1007/s40009-013-0147-x.

J. P. Singh $(\bowtie) \cdot$ A. K. Jaiswal · P. Patamajhi

Transfer of Technology Division, Indian Institute of Natural

Resins and Gums, Ranchi 834 010, India

e-mail: jpsingh_1258@yahoo.co.in

A. K. Jaiswal

e-mail: jaiswalak59@yahoo.co.in

M. Monobrullah

Lac Production Division, Indian Institute of Natural Resins and

Gums, Ranchi 834 010, India

e-mail: manawar69@yahoo.com 